\title{
In vivo chlorine-35, sodium-23 and proton magnetic resonance imaging of the rat brain
}

S. Kirsch ${ }^{1}$, M. Augath ${ }^{2}$, D. Seiffge ${ }^{3}$, L. Schilling ${ }^{3}$, and L. R. Schad ${ }^{1}$

${ }^{1}$ Computer Assisted Clinical Medicine, Medical Faculty Mannheim, University of Heidelberg, Mannheim, Germany, ${ }^{2}$ Department of Physiology of Cognitive Processes, Max Planck Institute for Biological Cybernetics, Tuebingen, Germany, ${ }^{3}$ Division of Neurosurgical Research, Medical Faculty Mannheim, University of Heidelberg,

Mannheim, Germany

\section{Introduction}

Chloride $\left(\mathrm{Cl}^{-}\right)$is the most abundant anion in the mammal organism playing an important role in many cellular processes. For instance, plasma membrane $\mathrm{Cl}^{-}$currents are important for the regulation of excitability in nerve and muscle. Moreover, $\mathrm{Cl}^{-}$ions play a crucial role in controlling the ionic composition of the cytoplasm and the volume of cells [1]. In order to investigate the feasibility of combined in vivo ${ }^{35} \mathrm{Cl}$, ${ }^{23} \mathrm{Na}$ and ${ }^{1} \mathrm{H} \mathrm{MRI}$ we developed a rf coil setup to measure ${ }^{35} \mathrm{Cl},{ }^{23} \mathrm{Na}$ and ${ }^{1} \mathrm{H}$ signals in one scanning session without moving the subject or changing the setup.

\section{Material and Methods}

For the ${ }^{1} \mathrm{H}$ and ${ }^{23} \mathrm{Na}$ measurements we used a linear double tuned volume resonator with an inner diameter of $7 \mathrm{~cm}$ from Bruker (Ettlingen, Germany). Additionally, we placed a surface coil on the head of the animal that operated at the resonance frequency of ${ }^{35} \mathrm{Cl}$ at $9.4 \mathrm{~T}$ of $39.2 \mathrm{MHz}$. This coil was constructed from silver wire with $3 \mathrm{~mm}$ diameter. A single loop of $35 \mathrm{~mm}$ diameter was bent on a $35 \mathrm{~mm}$ plexiglass half cylinder to achieve an optimal filling factor for a rat head. The ${ }^{35} \mathrm{Cl}$ coil was built large enough to cover the whole brain for sure and is glued to the plexiglass half cylinder to which it was bent.

Proton imaging was performed using a multi slice multi echo (MSME) sequence with $T R=2000 \mathrm{~ms}, T E_{1}=13 \mathrm{~ms}$ and $T E_{2}=65 \mathrm{~ms}$ (two images per slice). The field of view (FOV) was $64 \times 64 \mathrm{~mm}^{2}$ at a matrix of $256 \times 256$ with 9 coronal slices of 3 mm thickness and an inter-slice distance of $3.5 \mathrm{~mm}$. The total measurement time $(T A)$ was 6 min $24 \mathrm{sec}$.

The ${ }^{23} \mathrm{Na}$ and ${ }^{35} \mathrm{Cl}$ imaging was done using a slice selective ultra short echo time (UTE) pulse sequence with radial k-space acquisition [2]. For both nuclei 3 coronal slices with FOV $=64 \times 64 \mathrm{~mm}^{2}$, matrix of $64 \times 64$, slice thickness $=3 \mathrm{~mm}$ and an inter-slice distance of $3.5 \mathrm{~mm}$ were measured. The positions of the 3 slices were matched with the slice positions of the corresponding ${ }^{1} \mathrm{H}$ images by means of the scanner software Paravision ${ }^{\circledR}$. The parameters for the ${ }^{23} \mathrm{Na}$ imaging were $T R=40 \mathrm{~ms}, T E=0.321 \mathrm{~ms}$, readout bandwidth $=25 \mathrm{kHz} / \mathrm{FOV}$, number of averages $=225$ and $T A=30 \mathrm{~min} 17 \mathrm{sec}$. For the ${ }^{35} \mathrm{Cl}$ imaging the following parameters were used: $T R=40 \mathrm{~ms}, T E=0.448 \mathrm{~ms}$, readout bandwidth $=25 \mathrm{kHz} / \mathrm{FOV}$,
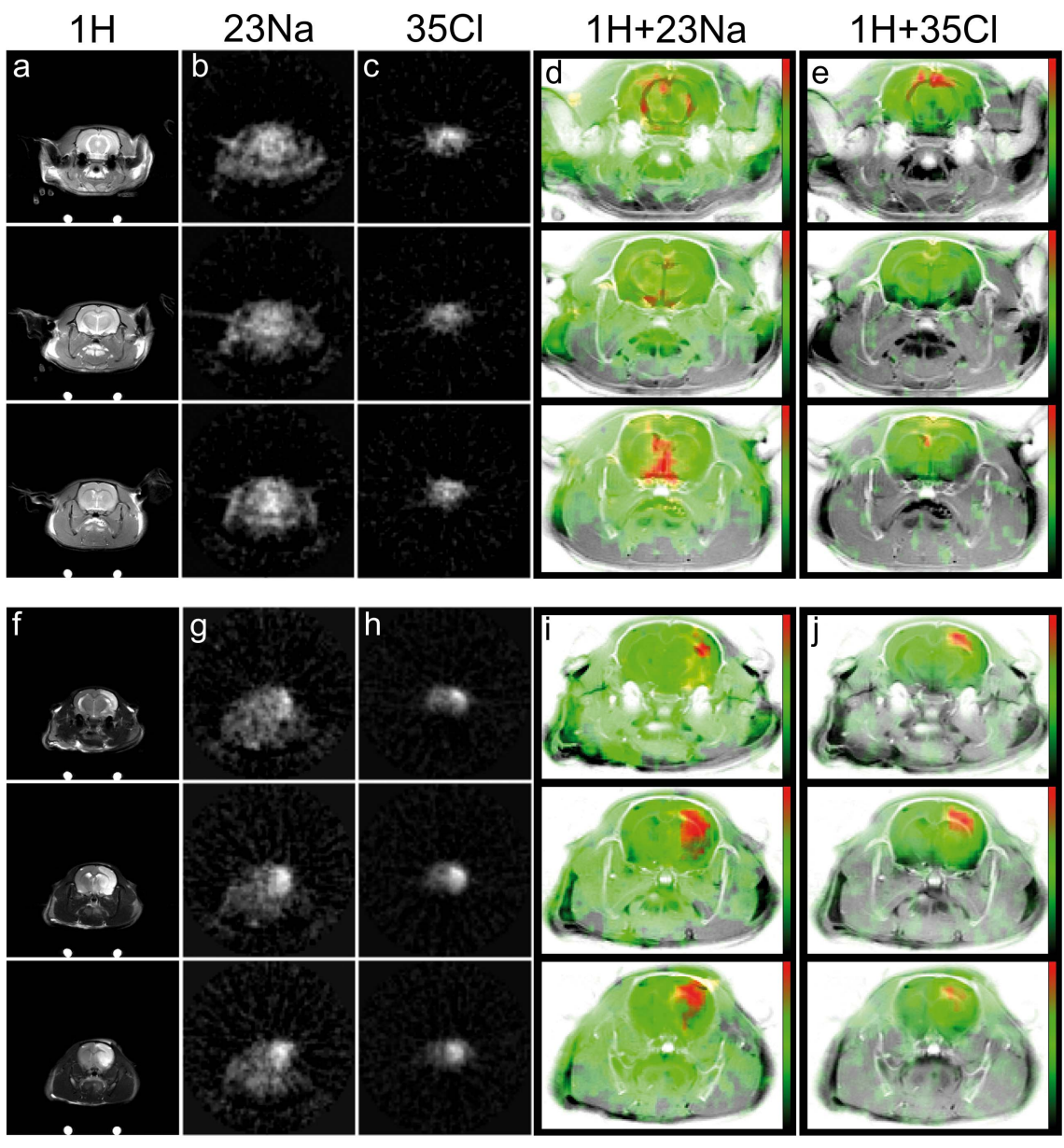
number of averages $=455$ and $T A=1 \mathrm{~h} 1 \mathrm{~min}$.

\section{Results and Discussion}

Multinuclear MRI of ${ }^{35} \mathrm{Cl},{ }^{23} \mathrm{Na}$ and ${ }^{1} \mathrm{H}$ was applied on the head of a healthy rat and on a rat displaying a focal cerebral infarction in the right hemisphere of the brain. Columns a-e show the results of the in vivo MRI on a healthy rat whereas columns $f-j$ show the results measured on a rat displaying a focal cerebral infraction. In the $T_{2}$ weighted ${ }^{1} \mathrm{H}$ images the area of infarction can be identified by the brighter areas in the right hemisphere of the brain due to ischemic swelling. Similar behaviour is observed in the ${ }^{23} \mathrm{Na}$ and ${ }^{35} \mathrm{Cl}$ images. Compared to the healthy tissue, a signal enhancement of a factor of $2.9\left({ }^{23} \mathrm{Na}\right)$ and of $2.2\left({ }^{35} \mathrm{Cl}\right)$ is observed in the area of infraction. The increase in signal is attributed to an increase in concentration of sodium and chloride ions. Note, the ${ }^{35} \mathrm{Cl}$ images were measured with a surface coil therefore mainly the brain of the rat is visible in the corresponding images (column $\mathrm{c}+\mathrm{h}$ ).

The coil setup and the measurement parameters of the ${ }^{35} \mathrm{Cl}$ and ${ }^{23} \mathrm{Na}$ MRI were a compromise in order to achieve almost the same image quality (SNR and resolution). Despite the fact that the signal intensity of ${ }^{35} \mathrm{Cl}$ is expected to be approx. 9.6 times lower than the signal intensity of ${ }^{23} \mathrm{Na}$, the ${ }^{35} \mathrm{Cl}$ signal was sufficient to perform in vivo ${ }^{35} \mathrm{Cl} \mathrm{MRI}$ with acceptable image quality in a measurement time of $1 \mathrm{~h}$. The total measurement time for the multinuclear MRI was $2 \mathrm{~h} .{ }^{35} \mathrm{Cl} \mathrm{MRI}$ allows non-invasive in vivo studies on pathologies or physiological processes which result in a change of $\mathrm{Cl}^{-}$ concentrations. Since chloride and sodium ions are transported concurrently, combined in vivo ${ }^{35} \mathrm{Cl},{ }^{23} \mathrm{Na}$ and ${ }^{1} \mathrm{H}$ MRI may provide a new approach to study diseases like stroke, ischemia or cystic fibrosis.

\section{References:}

[1] Jentsch TJ et al., Physiol. Rev. 2002; 82: 503-568.
[2] Robson MD et al., J. Comput. Assist. Tomogr. 2003; 27(6): 825-846. 